\title{
The Effect of Diabetes Camp on Glycemic Variability in Children and Adolescents with Type 1 Diabetes Mellitus
}

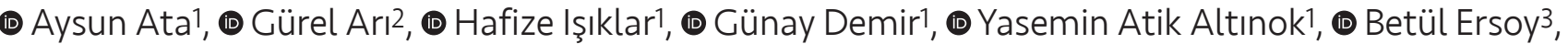 \\ (1) Samim Özen1', (1) Şükran Darcan¹, (1) Damla Gökşen¹
}

${ }^{1}$ Ege University Faculty of Medicine, Department of Pediatric Endocrinology, Izmir, Turkey

${ }^{2}$ American Collegiate Institute, İzmir, Turkey

${ }^{3}$ Celal Bayar University Faculty of Medicine, Department of Pediatric Endocrinology, Manisa, Turkey

\begin{abstract}
Aim: Glycemic variability can be affected in diabetes camps as a result of sports, social activities and nutrition. Close glucose monitoring is necessary to reduce glycemic variability, especially hypoglycemia. The aim assessment of glycemic variability and time in range by use of the flash glucose monitoring system (FGMS) in children and adolescents with type 1 diabetes.

Materials and Methods: Thirty-three children and adolescents between 10-18 years of age who participated in the 2018 diabetes camp of Ege University were included. Their glycemic variability indexes were recorded.

Results: The mean age and duration of diabetes mellitus in the study group was $13.3 \pm 0.5$ and $4.9 \pm 0.7$ years respectively. Twelve (43\%) of the participants were boys and 16 (57\%) were girls. Ten (35.7\%) of the participants used continuous subcutaneous insulin infusion (CSII) pump therapy while 18 (64.3\%) used multiple dose insulin therapy. When the participants were evaluated according to time in range (TIR), the duration of TIR increased, and level 1 and level 2 hyperglycemia decreased during the camp. Participants using CSII had spent more time in level 2 hypoglycemia before camp, but during and after the camp, similar values were reached for both groups. Before the camp, participants with good metabolic control had a longer duration of hypoglycemia than those participants with poor metabolic control. During and after the camp, level 1 and level 2 hypoglycemia periods were similar between the two groups.

Conclusion: In diabetes camp, healthy diet, regular exercise, and close glycemic control improve glycemic variability. By using FGMS, normoglycemia periods can be increased without increasing hypoglycemic attacks. As a result, using FGMS had a positive effect on diabetes management and the control of hypoglycemia periods during the diabetes camp.
\end{abstract}

Keywords: Diabetes camp, glycemic variability, flash glucose monitoring system

\section{Introduction}

In children and adolescents, glycemic variability, hypoglycemia and glycemic excursions are seen more than in adults due to their unpredictable activity, eating habits and hormonal changes (1). Either by using multiple dose insulin (MDI) or continuous subcutaneous insulin infusion (CSII) treatments, persons with type 1 diabetes mellitus have to monitor their blood glucose frequently in order to improve metabolic control. The burdens of self-monitoring of blood glucose (SMBC) include pain, disturbance of sleep 
due to night-time tests, inconvenience and embarrassment (2). It also has many limitations including insufficient identification of glycemic variability and hyperglycemic or hypoglycemic episodes due to intermittent monitoring, the unreliability of individual recorded data, and inadequate compliance (3). With the help of FGMS Abbott FreeStyle Libre, glucose levels are checked by scanning the sensor with a reader, thus eliminating the need for SMBG testing (4). It reports the current glucose concentration, glucose trends, and displays the previous 8 hours as a trend $(5,6)$. The aim of this study was to evaluate the duration of level 1 and level 2 hyperglycemia, time in range (TIR), and level 1 and level 2 hypoglycemia percentages in type 1 diabetic children and adolescents, by means of Abbott FreeStyle Libre FGMS, during a summer camp.

\section{Materials and Methods}

A retrospective study with type 1 diabetic children and adolescents aged 10-18 participating in a summer camp was conducted.

All participants gave written informed consent. This study was registered and approved by the ethics committee of Ege University with approval number 20-11.1T/45 and conducted in accordance with the Declaration of Helsinki.

The inclusion criteria were being between 10-18 years, a diagnosis of type 1 diabetes mellitus at least 1 year prior to the camp, the absence of any disease that could impair exercise capacity and a willingness to participate in the study. The medical staff, who supported the children during the camp, consisted of nutritionists, nurses of diabetology, pediatric assistant doctors, students, and specialists in pediatric endocrinology and diabetes.

All camp participants who were using Abbott FreeStyle Libre sensor were included in the study. However, routine glucose control measurements for therapeutic decisions were made by Accu Check Performa glucometer. Participants at the camp performed activities such as swimming, cycling, running and dancing for a minimum of 2 hours per day. The duration of the camp was 5 days. After camp was completed, data from FGMS was downloaded to a computer by specially designed software that created a series of reports of the glycemic picture 5 days before, 5 days during and 5 days after the camp. TIR was defined as the percentage of glucose readings and the time between 70-180 mg/dL (3.9-10 mmol/L). Level 1 hyperglycemia was defined as the percentage of readings and time between 181-250 mg/dL (10-13.9 mmol/L). Level 2 hyperglycemia was defined as the percentage of readings and time greater than $250 \mathrm{mg} / \mathrm{dl}$ (13.9 mmol/L). Level 1 and 2 hypoglycemia were defined as the percentage of readings and time between 69-54 mg/dL (3.9-3 mmol/L) and the time less than $54 \mathrm{mg} /$ $\mathrm{dL}$ (3 $\mathrm{mmol} / \mathrm{L}$ ) respectively (6). All raw data was classified according to TIR, hypo- or hyperglycemia.

In year 2020, standard deviation (SD) and coefficient of variation (CV) calculation program was added to Libre infrastructure. Unfortunately in 2018 in the Turkish version of software of Libre, the personal SD and CV was not calculated. For this reason, each participants' intrapersonal mean and SD of all recorded glycemic measurements (approximately 1,500) were calculated by researchers and for the coefficient of variance, the mean/SD formula was used (7).

\section{Statistical Analysis}

Analysis was carried out using SPSS for Windows 25.0, descriptive statistics are reported using mean \pm SD for normally distributed variables, and median for skewed data. Since the sample size was smaller than 30 , it does not meet the normality assumption of a t-test. Thus, groups in this study were compared by Mann-Whitney $U$ test, which is a non-parametric equivalent of the 2-sample t-test. Trends across more than 2 groups were ANOVA and Freidman analysis. P-values of less than 0.05 were considered statistically significant.

\section{Results}

Of the 33 participants, 5 were not included in the study due to early detachment of the sensor. Mean age and duration of diabetes mellitus were $13.3 \pm 0.5$ and $4.9 \pm 0.7$ years respectively. Twelve $(43 \%)$ of the participants were male and $16(57 \%)$ were female. Forty percent $(n=12)$ of the participants' diabetes duration was greater than 5 years. Ten (35.7\%) of the participants were using a CSII pump while 18 (64.3\%) were using MDI therapy. The mean glucose of all the participants before, during, and after camp were $199 \pm 52.5 \mathrm{mg} / \mathrm{dL}(11 \pm 2.9 \mathrm{mmol} / \mathrm{L}), 171 \pm 32.1 \mathrm{mg} / \mathrm{dL}$ $(9.5 \pm 1.8 \mathrm{mmol} / \mathrm{L})$, and $194 \pm 45.2 \mathrm{mg} / \mathrm{dL}(10.8 \pm 2.5 \mathrm{mmol} / \mathrm{L})$ respectively (Table I).

The percentage of readings within TIR was $60.3 \pm 15.3 \%$ during the camp, $47.4 \pm 17.7 \%$ before the camp and $44.1 \pm 17.5 \%$ after the camp ( $p=0.005)$. Participants with poor metabolic control had an increased percentage of TIR in comparison to their pre-camp values ( $p=0.003$, Table II). As was expected, pre-camp TIR values were higher in the good metabolic control group in comparison to the poor metabolic control group ( $p=0.037)$. However, no differences were found during or after the camp. In the poor metabolic control group, level 2 hyperglycemia values were lower during the camp than their pre- and post-camp values $(p=0.039)$. Those 
participants with good metabolic control had longer periods of level 2 hypoglycemia compared with the poor metabolic control group before the camp $(p=0.033)$ whereas the duration of level 2 hypoglycemia was similar during and after the camp (Table II).

The CSII and MDI groups had a similar percentage of TIR, level 1 and level 2 hyperglycemia, and level 1 hypoglycemia values before, during and after the camp. In the CSII group, the duration of level 2 hypoglycemia was more than the MDI group before the camp $(p=0.03)$. Similar values were reached during and after the camp between the groups (Table III). The mean HbAic of the last year before summer camp was $7.7 \%(61 \mathrm{mmol} / \mathrm{mol})$ in the CSII group and $8.4 \%$ (68 $\mathrm{mmol} / \mathrm{mol}$ ) in the MDI group.

The total daily insulin dosage before and during the camp was not significantly different $(0.81 \pm 0.23$ and $0.79 \pm 0.24 \mathrm{u} / \mathrm{kg}$ respectively). During the camp, basal insulin dosage was significantly lower than the pre-camp and post-camp values $(0.36 \pm 0.15,0.31 \pm 0.14$ and $0.38 \pm 0.14 \mathrm{u} / \mathrm{kg}$ respectively, $\mathrm{p}<0.001)$.

SD was $74.1 \pm 36.48$ before the camp, it was reduced to $67.4 \pm 31.6$ during the camp and increased to $74.95 \pm 30.10$ after the camp but this is statistically insignificant. CV before, during, and after the camp was $40.61 \%, 41.2 \%$, and $39.2 \%$, respectively.

\section{Discussion}

There have been significant changes in the management and treatment of type 1 DM with breakthroughs in technology. One of the challenges in diabetes, especially in children, is the measurement of capillary blood glucose. Many children do not measure blood glucose due to pain, loss of time and shame, and do not adequately manage

Table I. Duration of hypoglycemia, normoglycemia and hyperglycemia periods before, during and after summer camp

\begin{tabular}{|c|c|c|c|c|}
\hline & \multicolumn{4}{|c|}{ All participants $n=28$} \\
\hline & Before camp & During camp & After camp & p-value \\
\hline $\begin{array}{l}\text { Mean glucose readings } \mathrm{mg} / \mathrm{dL} \\
(\mathrm{mmol} / \mathrm{L})\end{array}$ & $\begin{array}{l}199 \pm 52.5 \\
(11 \pm 2.9)\end{array}$ & $\begin{array}{l}171 \pm 32.1 \\
(9.5 \pm 1.8)\end{array}$ & $\begin{array}{l}194 \pm 45.2 \\
(10.8 \pm 2.5)\end{array}$ & 0.002 \\
\hline Level 1 hypoglycemia (\%) & $2.07 \pm 2.85$ & $1.41 \pm 3.07$ & $0.7 \pm 1.31$ & 0.085 \\
\hline Level 2 hypoglycemia (\%) & $3.06 \pm 3.19$ & $3.36 \pm 2.41$ & $2.18 \pm 1.73$ & 0.280 \\
\hline Normoglycemia (\%) & $47.48 \pm 17.79$ & $60.35 \pm 15.35$ & $44.18 \pm 17.5$ & 0.002 \\
\hline Level 1 hyperglycemia (\%) & $24.38 \pm 6.86$ & $20.54 \pm 7.21$ & $27.63 \pm 9.42$ & 0.008 \\
\hline Level 2 hyperglycemia (\%) & $22.99 \pm 19.3$ & $14.23 \pm 11.52$ & $25.29 \pm 13.80$ & 0.032 \\
\hline Daily scan count (n) & $15.6 \pm 12.1$ & $51.89 \pm 33.61$ & $27.53 \pm 14.76$ & $<0.001$ \\
\hline
\end{tabular}

Table II. Duration of hypoglycemia, normoglycemia and hyperglycemia periods before, during and after summer camp according to metabolic control

\begin{tabular}{|c|c|c|c|c|c|c|c|c|}
\hline & \multicolumn{4}{|c|}{ HbA1c $\leq 7.5 \%$} & \multicolumn{4}{|c|}{ HbA1c>7.5 \% } \\
\hline & Before camp & During camp & After camp & p-value & Before camp & During camp & After camp & p-value \\
\hline $\begin{array}{l}\text { Level } 2 \\
\text { hypoglycemia \% }\end{array}$ & $3(0-11.9)$ & $0.2(0-13.1)$ & $0.1(0-5.1)$ & 0.013 & $0.4(0-5.5)$ & $3.5(0.2-7)$ & $2.3(0-5.5)$ & 0.460 \\
\hline $\begin{array}{l}\text { Level } 1 \\
\text { hypoglycemia \% }\end{array}$ & $3.7(0.4-11.9)$ & $2.6(0.4-7)$ & $1.8(0-4.9)$ & 0.165 & $1.6(0-7.9)$ & $0.1(0-6.9)$ & $0(0-2.8)$ & 0.404 \\
\hline TIR \% & $51.1(43.9-71.7)$ & $58(29.9-93)$ & $42.1(22.2-87.9)$ & 0.27 & $41.1(9.5-81.1)$ & $59.9(41.5-89)$ & $43.6(18.3-73.4)$ & 0.003 \\
\hline $\begin{array}{l}\text { Level } 1 \\
\text { hyperglycemia \% }\end{array}$ & $23.5(15.2-31.6)$ & $20.7(4.2-30.2)$ & $30.3(7-51.1)$ & 0.053 & $26.7(10.8-36.3)$ & $19.8(4.1-31.2)$ & $28(15.8-38.4)$ & 0.076 \\
\hline $\begin{array}{l}\text { Level } 2 \\
\text { hyperglycemia \% }\end{array}$ & $9.4(2.8-20.5)$ & $10.1(0-43.2)$ & $23.2(0-31.3)$ & 0.303 & $29.9(3.3-77.6)$ & $8.8(0.9-33.1)$ & $24(5.8-63.1)$ & 0.039 \\
\hline
\end{tabular}

Data are median (min-max), Time in range (TIR): 70-180 mg/dL (3.9-10 mmol/L), Level 1 hyperglycemia: 181-250 mg/dL (10-13.9 mmol/L), Level 2 hyperglycemia: >250 $\mathrm{mg} / \mathrm{dL}(13.9 \mathrm{mmol} / \mathrm{L})$, Level 1 hypoglycemia: $69-54 \mathrm{mg} / \mathrm{dL}$ ( $3.9-3 \mathrm{mmol} / \mathrm{L})$, Level 2 hypoglycemia: $<54 \mathrm{mg} / \mathrm{dL}$ (3 mmol/L)

Min: Minimum, max: Maximum 
Table III. Duration of hypoglycemia, normoglycemia and hyperglycemia periods before, during and after summer camp according to treatment method

\begin{tabular}{|c|c|c|c|c|c|c|c|c|}
\hline & \multicolumn{4}{|l|}{ CSII $(n=10)$} & \multicolumn{4}{|l|}{ MDI $(n=18)$} \\
\hline & Before camp & During camp & After camp & p-value & Before camp & During camp & After camp & p-value \\
\hline $\begin{array}{l}\text { Level } 2 \\
\text { hypoglycemia \% }\end{array}$ & $2.2(0.8-11.9)$ & $1.4(0-13.1)$ & $0.5(0-5.1)$ & 0.0242 & $0.1(0-5.5)$ & $0(0-6.9)$ & $0(0.8-2.8)$ & 0.71 \\
\hline $\begin{array}{l}\text { Level } 1 \\
\text { hypoglycemia \% }\end{array}$ & $3(1.3-11.9)$ & $5.4(0.4-6.2)$ & $2.5(0.2-5.5)$ & 0.432 & $1.4(0-8.8)$ & $2.1(0.2-7)$ & $2.1(0-5.5)$ & 0.5 \\
\hline Normoglycemia \% & $45.2(24-51.8)$ & $56.5(41.5-66.7)$ & $40.4(24.2-47.2)$ & 0.016 & $50.6(9.5-81.1)$ & $60.3(29.9-93)$ & $44.5(18.7-87.9)$ & 0.024 \\
\hline $\begin{array}{l}\text { Level } 1 \\
\text { hyperglycemia \% }\end{array}$ & $29.5(19.6-31.6)$ & $20.6(17.7-29.1)$ & $31.3(17.1-33.7)$ & 0.011 & $24.1(10.1-31.1)$ & $19.4(4.1-31.2)$ & $28(7-51.1)$ & 0.032 \\
\hline $\begin{array}{l}\text { Level } 2 \\
\text { hyperglycemia \% }\end{array}$ & $19.3(9.4-43.2)$ & $11.9(4.7-39.5)$ & $\begin{array}{l}30.6(16.2- \\
38.8)\end{array}$ & 0.056 & $15.9(2.8-77.6)$ & $9.4(0-43.2)$ & $23.5(0-63.1)$ & 0.091 \\
\hline
\end{tabular}

Data are median (min-max), Time in range (TIR): 70-180 mg/dL (3.9-10 mmol/L), Level 1 hyperglycemia: 181-250 mg/dL (10-13.9 mmol/L), Level 2 hyperglycemia: >250 $\mathrm{mg} / \mathrm{dL}$ (13.9 mmol/L), Level 1 hypoglycemia: $69-54 \mathrm{mg} / \mathrm{dL}$ ( $3.9-3 \mathrm{mmol} / \mathrm{L})$, Level 2 hypoglycemia: <54 mg/dL (3 mmol/L).

Min: Minimum, max: Maximum, CSII: Continuous subcutaneous insulin infusion, MDI: Multiple dose insulin

diabetes, especially when they are away from parental control, such as at school (8). FGMS was developed to replace capillary blood glucose measurement and contributes to the management of diabetes by recording glucose values every 15 minutes, showing the trend of the previous 8 hours and creating graphs of glycemic variability (9).

The importance of exercise in the treatment of diabetes is indisputably known, but each individual's glycemic variability with exercise is different and the effect on blood glucose depends on the duration and type of exercise $(10,11)$. Although exercise rules are determined by many associations, there are individual differences in practice $(12,13)$. Many persons with diabetes avoid sports because of the fear of hypoglycemia, the difficulty in follow-up of strict SMBG, and a lack of knowledge about exercise management (14). Diabetes camps are one of the most intensive experiences for exercise and contribute to exercise training $(15,16)$.

Although insulin dosage is decreased in diabetes camps, hypoglycemia is seen frequently with the effects of strict exercise (17-19). We observed that increasing the number of scans by Abbott FreeStyle Libre and promoting strict exercise increased the duration of normoglycemia during the camp. When the participants returned to their natural routine, similar results to pre-camp values were observed; positive motivation was not permanent, and it seems that permanent lifestyle changes are obligatory to improve metabolic control. Parallel to our results, various studies show that those persons with the poorest metabolic control had the greatest metabolic improvements during the camp, but this is not sustained after the camp (20).
In the CSII group, the duration of level 1 hypoglycemia was longer before the camp. This was due to the fact that the pumps are not reinforced by the sensor and lower HbA1c values are present in CSII group. However, there was no difference in the duration of level 1 hypoglycemia according to the treatment model during the camp, suggesting that the lack of knowledge about hypoglycemia awareness/ management in this group might be the reason.

Glycemic variability is a favorite target of scientific research in diabetology. It was found to be related to microvascular complications (21). In non-diabetic persons, after intense exercise, despite no changes in mean blood glucose levels, there is increased glycemic variability and increased periods of hypoglycemia (10). Although light exercise and glycemic variability in type 2 diabetes mellitus has been studied, the information about the effect of exercise on glycemic variability in children with type 1 diabetes was inadequate $(11,22)$. It is hoped that treatment approaches that will reduce glycemic variability during exercise will be found, but it needs to be clarified according to exercise type and treatment modalities. As we investigate the literature, our study was the first of its kind using FGMS during a summer camp in a pediatric sub-population evaluating glycemic variability calculated as CV. There are two other studies which evaluated the accuracy and satisfaction of Abbott FreeStyle Libre which concluded that the FSL is accurate in children. However, its accuracy depends on the glucose trend and Abbott FreeStyle Libre user's satisfaction survey revealed that most of the respondents rated satisfaction with Abbott FreeStyle Libre positively $(23,24)$. In a summer camp conducted in Slovenia, children with type 1 
diabetes using CSII were investigated. They found that CGM was as safe and effective as SMBG, and reduced the time spent in hyperglycemia in a sub-population of children with suboptimal glycemic control.

\section{Study Limitations}

In this study, the number of capillary blood glucose measurements were not recorded, a quality of life and the Abbott FreeStyle Libre satisfaction questionnaire were not applied, and unexpected events were not recorded.

\section{Conclusion}

Considering all the data, due to its easy usability, guidance with diabetes management, lack of requirement for calibration and good participant satisfaction, Abbott FreeStyle Libre can be used during summer camp. With its contribution, the duration of normoglycemia can be increased without increasing the duration of hypoglycemia and glycemic variability.

\section{Ethics}

Ethics Committee Approval: The study was registered and approved by the ethics committee of Ege University with approval number 20-11.1T/45 and conducted in accordance with the Declaration of Helsinki.

Informed Consent: All participants gave written informed consent.

Peer-review: Externally peer-reviewed.

\section{Authorship Contributions}

Concept: A.A., Ş.D., Design: G.A., G.D., Data Collection or Processing: H.I., D.G., Analysis or Interpretation: Ş.D., Literature Search: B.E., Y.A.A., Writing: A.A., S.Ö.

Conflict of Interest: No conflict of interest was declared by the authors.

Financial Disclosure: The authors declared that this study received no financial support.

\section{References}

1. Mayer-Davis E), Kahkoska AR, Jefferies C, et al. ISPAD Clinical Practice Consensus Guidelines 2018: definition, epidemiology, and classification of diabetes in children and adolescents. Pediatr Diabetes 2018; 19:7-19.

2. Wagner J, Malchoff C, Abbott C. Invasiveness as a barrier to self-monitoring of blood glucose in diabetes. Diabetes Technol Ther 2005; 7:612-9.

3. Rodbard D. Continuous glucose monitoring: a review of successes, challenges, and opportunities. Diabetes Technol Ther 2016; 18(Suppl 2):S2-13. doi: 10.1089/dia.2015.0417.

4. Ólafsdóttir AF, Attvall S, Sandgren $U$, et al. A clinical trial of the accuracy and treatment experience of the flash glucose monitor freestyle libre in adults with type 1 diabetes. Diabetes Technol Ther 2017; 19:164-72.

5. Bailey T, Bode BW, Christiansen MP, Klaff L), Alva S. the performance and usability of a factory-calibrated flash glucose monitoring system. Diabetes Technol Ther 2015; 17:787-94.

6. Heinemann L, Freckmann C. CGM versus FGM; or, continuous glucose monitoring is not flash glucose monitoring. I Diabetes Sci Technol 2015; 9:947-50.

7. Battelino T, Danne T, Bergenstal RM, et al. Clinical Targets for Continuous Glucose Monitoring Data Interpretation: Recommendations From the International Consensus on Time in Range. Diabetes Care 2019; 42:1593-603.

8. Miller KM, Beck RW, Bergenstal RM, et al. Evidence of a strong association between frequency of self-monitoring of blood glucose and hemoglobin a1c Levels in t1d exchange clinic registry participants. Diabetes Care 2013; 36:2009-14.

9. Mancini G, Berioli M, Santi E, et al. Flash glucose monitoring: a review of the literature with a special focus on type 1 diabetes. Nutrients 2018; 10:992.

10. Francois ME, Cosgrove SD, Walker NM, Lucas SJ, Black KE. Physiological responses to a five-day adventure race: Continuous blood glucose, hemodynamics and metabolites the 2012 GODZone field-study. J Exerc Sci Fit 2018; 16:78-82.

11. Van Dijk J-W, Manders RJF, Canfora EE, et al. Exercise and 24-h glycemic control: equal effects for all type 2 diabetes patients? Med Sci Sports Exerc 2013; 45:628-35.

12. Kennedy A, Narendran P, Andrews RC, Daley A, Greenfield SM. Attitudes and barriers to exercise in adults with a recent diagnosis of type 1 diabetes: a qualitative study of participants in the Exercise for Type 1 Diabetes (EXTOD) study. BMJ Open 2018; 8:e017813. doi: 10.1136/bmjopen-2017-017813.

13. Choleau C, Aubert C, Cahané M, Reach G. High day-to-day glucose variability: a frequent phenomenon in children and adolescents with type 1 diabetes attending summer camp. Diabetes Metab 2008; 34:46-51.

14. Riddell MC, Gallen IW, Smart CE, et al. Exercise management in type 1 diabetes: a consensus statement. Lancet Diabetes Endocrinol 2017; 5:377-90.

15. Semiz S, Özarslan Bilgin Ü, Bundak R, Bircan I. Summer camps for diabetic children: an experience in Antalya, Turkey. Acta Diabetol 2000; 37:197-200.

16. Tumini S, Anzellotti MT, Chiarelli F. Camps for Children with T1DM. Acta Bio Medica 2003; 74:32-4.

17. Braatvedt GD, Mildenhall L, Patten C, Harris G. Insulin requirements and metabolic control in children with diabetes mellitus attending a summer camp. Diabet Med / Br Diabet Assoc 1997; 14:258-61.

18. Barone MTU, Vivolo MA, Madden PB. Are diabetes camps effective? Diabetes Res Clin Pract 2016; 114:15-22.

19. Misuraca A, Di Gennaro M, Lioniello M, Duval M, Aloi G. Summer camps for diabetic children: an experience in Campania, Italy. Diabetes Res Clin Pract 1996; 32:91-6.

20. Post EM, Moore JD, Ihrke J, Aisenberg J. Fructosamine levels demonstrate improved glycemic control for some children attending a diabetes summer camp. Pediatr Diabetes 2000; 1:204-8. 
21. Prázný M, Škrha J, Šoupal J, Škrha J. Glycemic variability and microvascular complications of diabetes. Cas Lek Cesk 2017; 156:308-13.

22. Hill NE, Campbell C, Buchanan P, Knight M, Godsland IF, Oliver NS. Biochemical, physiological and psychological changes during endurance exercise in people with type 1 diabetes. I Diabetes Sci Technol 2017; 11:529-36.
23. Deja $G$, Kłeczek $M$, Chumięcki $M$, et al. The usefulness of the FlashStyle Libre system in glycemic control in children with type 1 diabetes during summer camp. Pediatr Endocrinol Diabetes Metab 2018; 24:11-9.

24. Szadkowska A, Gawrecki A, Michalak A, Zozulińska-Ziółkiewicz $D$, Fendler W, Mtynarski W. Flash glucose measurements in children with type 1 diabetes in real-life settings: to trust or not to trust? Diabetes Technol Ther 2018; 20:17-24. 